\section{EL DISCURSO MUSICAL COMO ARMA POLÍTICA EN LA OBRA DE ALEJO CARPENTIER}

\author{
Carlos Villanueva Abelairas \\ Universidad de Santiago \\ carlos.villanueva@usc.es
}

\section{MUSICAL DISCOURSE AS POLITICAL WEAPON IN THE WORKS OF ALEJO CARPENTIER}

\begin{abstract}
Alejo Carpentier became known as Art and Music critic: first from his early works in La Havana newspapers and magazines, being an active member of the "Minorista" group; and later, in Paris (1928), in his voluntary exile of Caracas (1945), or already incorporated to the Cuban revolution (1959), he starts to change the chronicle, the historical essay or the fiction stories into an authentic musical curtain of the life he portrays, as if it was a soundtrack, always with clear and didactic political premeditation. The shades and tools of his discourse will depend on the genre he manipulates: pure musicology for the deconstruction of the musical space (La Música en Cuba); the ethnic narration for the foundation of Afrocubanism ( $i E$ Écue-yambao!); the counterpoint of "revolutionary" musics (La consagración de la primavera); the chronicle of primitive worlds (Los pasos perdidos) or the pure humor to caricature a dictatorship (El recurso del método). Always through daily chronicles, he uses the example, the quote or the musical variation as a teacher, trying to transform Life, Society, Aesthetics and the people.
\end{abstract}

KEY WORDS: Carpentier; musical criticism; nationalism; Cuba;Stravinsky.

\begin{abstract}
RESUMEN: Alejo Carpentier se dio a conocer como crítico de arte y de música: desde sus trabajos en periódicos y revistas habaneras, siendo miembro activo del grupo "Minorista"; posteriormente, desde París (1928), en su exilio voluntario de Caracas (1945), o ya incorporado a la revolución castrista (1959), va convirtiendo la crónica, el ensayo histórico o el relato de ficción en un auténtico telón musical de la vida que retrata, como si de una banda sonora se tratara, siempre con clara y didáctica intencionalidad política. Los matices y herramientas de su discurso dependerán del género que manipula: la pura musicología para la deconstrucción del espacio musical (La Música en Cuba); el relato étnico para la fundamentación del afrocubanismo (iÉcue-yamba-o!); el contrapunto de músicas "revolucionarias" (La consagración de la primavera); la crónica de mundos primitivos (Los pasos perdidos), o el puro humor para caricaturizar una dictadura (El recurso del método). Y, siempre, la crónica diaria, usando como maestro el ejemplo, la cita, o la variación musical, intentando transformar la vida, la sociedad, la estética y las personas.
\end{abstract}

PALABRAS CLAVE: Carpentier; critica musical; nacionalismo; Cuba; Stravinsky.

"La verdadera música tiene el poder de sugerir ideas análogas en cerebros distintos" (Ch. Baudelaire)

Nada mejor para comenzar que una paradoja: Alejo Carpentier posee un currículo "político" intachable: en las primeras trincheras del periodismo antimachadista; crítico musical y portavoz oficial, vanguardista y antisistema del movimiento "minorista" cubano; padeciendo cárcel y persecución; exiliado en París, en México o en Caracas; incorporado al equipo de la revolución castrista en su retorno a la Isla; portavoz y referente de un modelo estético y político... Un modelo a seguir, como se sintetiza en el documento de constitución de la cátedra Carpentier de la Universidad de La Habana':
Resolución rectoral por la que se crea la cátedra ALEJO CARPENTIER VALMONT IN MEMORIAM 347/81

POR CUANTO: Alejo Carpentier Valmont laboró como un profesor de Historia de la Cultura de la Escuela de Historia de la Universidad de La Habana y mantuvo una consecuente actividad pedagógica y cultural sobre bases revolucionarias y marxistas-leninistas.

POR CUANTO: en vida, personalidad y obra de este escritor cubano ha colocado en un cimero lugar, dentro del continente latinoamericano en el mundo, la literatura y la cultura de nuestro país. 
POR CUANTO: debe materializarse un permanente homenaje a este insigne escritor y profesor, de manera que su obra se proyecte en la diaria labor de profesores y educandos del área docente que corresponde. RESUELVE LA CREACIÓN, etc...

3 de marzo de 1981, "año del XX Aniversario de Girón".

Un cubano de raza, en suma. No obstante, y aquí la paradoja, tanto su pedigrí de cubano como su "sinceridad" política o estética fueron cuestionadas en diversas ocasiones, antes y ahora, por razones varias: por su elitismo orteguiano (muy a su pesar); por su afrancesado refinamiento (con fuerte acento nunca perdido y con su partida de nacimiento emitida en Lausana-Suiza); por su pertenencia funcionarial al régimen castrista; por su irreductible posicionamiento "anti imperio" (amplificado por el imparable crecimiento de su propia fama como narrador y por el uso partidista desde La Habana de su persona y de su obra); $y_{\text {, }}$ sin duda, en lo que más nos atañe, por su particular acción deconstructiva en La Música en Cuba (Carpentier, 1946).

Nos interesa para la ocasión, como punto de partida, el análisis del compromiso utópico carpenteriano llevado a cabo por Th. Brennan (1997, 259), quien -como ya dije en otra ocasión- "resalta los puntos de interés que, a pesar de las limitaciones metodológicas y el devenir decadente de su discurso afro-cubano, siguen pareciéndonos atractivos, debido en parte al aislamiento de Cuba como último bastión de la antiglobalización y cabeza de la lucha por los paises del Tercer Mundo, lo que Carpentier defendió; también debido a que, aunque la Cuba revolucionaria no ha jugado un papel destacado en la teoría cultural AméricaEuropa, el ejemplo de Carpentier es la llave para entender la contribución de la etnografía actual para la comprensión de los estudios sobre cultura" (Villanueva, 2005a, 329).

Pablo Neruda, en sus memorias (Neruda, 1974), ya se refería a la absoluta incapacidad del joven Carpentier, recién instalado en París en 1928, para comprometerse políticamente; afirmación que nos parece, más bien, anticipada, coyuntural e interesada, pero que otros, como Julio Cortazar, también suscribirian tras algún ajuste de cuentas. Todo ello no es óbice para que Mario Vargas Llosa, tan distante políticamente de Alejo tras la ruptura parisina, reconozca el influjo ejercido por el cubano en el plano literario: "Inmediatamente -nos dice el reciente Nobel de literatura- fui absorbido por la magia de El reino de este mundo y la transfiguración mítica que la prosa de Carpentier hace de los primeros intentos independentistas en Haití" (Vargas Llosa, 2010, 29).

Traigo aquí a colación a Neruda no tanto porque sea la suya una opinión generalizada que pretenda yo suscribir, sino porque nos ayuda a contextualizar mejor La consagración de la primavera, y por el compromiso narrativo testimonial que Alejo asume al transformar premeditadamente una serie de relatos sueltos en una obra unitaria, comprometida, y que se convierte en el primer gran relato épico sobre la Revolución cubana de 1959; así lo expone con buenos argumentos Ambrosio Fornet $(2008,205)$.

En cualquier caso, sus compañeros minoristas habaneros tuvieron ocasión de posicionarse sobre su compromiso político y estético, dependiendo el dictamen de sus experiencias y conflictos personales con el musicólogo y novelista. Así, J. Marinello $(1937,84)$ nos dice, en referencia al afrocubanismo carpenteriano:

[...] Alejo Carpentier es, como se sabe, una de las sensibilidades más finas y cultivadas de las nuevas generaciones. Su curiosidad generosa iguala a su capacidad técnica. Es tan artista como hombre de letras, tan ansioso de su primitivismo como esclavo de refinamientos. En relación con lo cubano se agrava esta posición contradictoria. Vivió entre nosotros largos años; partió hacia París en la primera juventud, pero acusada ya, en armoniosa precocidad, su personalidad artística. Tenido en La Habana como extranjero (...) vivió entre nosotros una peregrina indefinición: lo criollo le atrajo poderosamente; sintió de cerca lo africano trasplantado a la Isla, el son del mulato, el tono coloquial, pero no supo redimirse la extranjería. Impelido por su sed artística y su hambre inquisitiva trabó contacto esotérico con nuestro negros y frecuentó cabildos y bembés. Los vio por dentro, pero no se metió en ellos; les sorprendió el perfil, les robó el acento, no les llegó a las vísceras recónditas. Si para muchos cubanos blancos y aún para algún cubano negro, la intimidad afrocriolla en sus valores más definidos, es teatro y pictoricidad, ¿no habria de serlo para un adolescente nacido en la vieja cultura y que habia ido hacia lo negro como una fiesta de los sentidos y una prueba de sus capacidades cultas?

De un extremo al otro de las corrientes de opinión, podemos seguir a Th. Brennan (1977), F. Janney (1981), o a R. González Echevarría (1988 y 2004), en una línea 
valorativa más esteticista del escritor cubano; y del otro, a J. A. Portuondo (1976) o A. Cairo (1978 y 1988), en una lectura más "dialéctica" y consecuente con la actuación política de Alejo, abierta y publicitada traspasado el año 1959; para acabar, cabalmente, transitando en una vía intermedia más académica que analice las relaciones de Carpentier con la creatividad literaria y musical, en la línea marcada por Carmen Vásquez (1978), o yo mismo (C. Villanueva, 2005a).

Al referirnos a Carpentier, conviene tener presente "los numerosos obstáculos [que] encuentra el investigador actual. Entre ellos, la carencia de materiales de gran importancia, como son sus manuscritos, mecanoscritos, el epistolario y su biblioteca, el acceso a artículos suyos que, pese a las selecciones y compilaciones existentes, están atomizados en publicaciones disímiles, muchas de difícil consulta por la dispersión de los fondos que las contienen y el estado de las mismas" (Baujín, 2003, 7).

En todo caso, y dejando a un lado sus intenciones o sus desencuentros, en su posicionamiento ensayístico, histórico o crítico hay una carga implícita de contenido político: algo tan sencillo como pretender cambiar el mundo que le rodea. Alejo, además, "elige las armas estilísticas adecuadas, las emplea con una singular destreza y es coherente en el uso de recursos estéticos a la hora de emitir y lexicalizar eslóganes y fórmulas que bien podrían cambiar/haber cambiado su querido mundo cubano" (Villanueva, 2005b, 117).

\section{Carpentier cronista musical}

Nos atrevemos a afirmar que la gigantesca aportación musical de Carpentier supone, básicamente, una inmensa crónica fraccionable en temas, momentos, géneros, según el medio para el que escribe y el tipo de receptor. Así, La música en Cuba, una obra de culto para la musicología cubana, el relato minucioso y testimonial de La Consagración de la primavera, sus incursiones antropológicas en !Écue-yamba-O!, el viaje iniciático de Los pasos perdidos, 0 las innumerables crónicas diarias desde Caracas o París, recopiladas por el mismo Carpentier (1964), por Zoila Gómez (1980) o por Radamés Giro (1994), entre otros, constituyen un amplio retablo narrativo, intrincado por sus infinitos intereses y su desbordante erudición, pero perfectamente unitario, coherente y genésico en lo que a intencionalidad política se refiere.

El periodismo testimonial es asumido por Carpentier, también, como el podio ideal desde el que cumplir su encomienda de revelar, instruir y educar a un continente desfasado y latiendo a destiempo en la marcha de la historia, en las nociones y los derroteros más avanzados del Arte y del pensamiento en general. "Ello le permite, a la vez, introducir en la praxis diaria transgresiones eficaces, a través de contaminaciones de recursos procedentes de otros espacios como el ensayo y la ficción narrativa. De la misma forma, el periodismo late positivamente en sus empeños teóricos, ensayísticos y narrativos" (Baujín, 2003, 64).

Tomando notas entre bambalinas, entrevistando a los protagonistas, visitando los cafés-teatro donde actuaba Amadeo Roldán, recensionando libros o criticando exposiciones..., Carpentier alcanza enseguida el reconocimiento de su círculo de amigos (y el de sus enemigos), como persona sólida, al tanto de las últimas novedades de la vanguardia, y muy crítico con la burguesía "pasadista y edulcorada" de la ópera habanera o de la asociación de conciertos Pro Musica..., "trabajo de calle en el que, además, se escuchaban los grupos soneros y el latido musical de La Habana profunda; pero tras su incorporación a la Sociedad de Folklore, fundada en 1923 por Fernando Ortiz, Alejo orientará también sus pasos de "curioso impertinente" hacia otras formas musicales asociadas a las fiestas, populares, religiosas o iniciáticas, en casas, solares o al aire libre" (Cairo, 2005, 70). En esta línea amistosa y admirativa sobre su labor se decanta el poeta Nicolás Guillén $(1976,53)$ :

En el madurar y crecer de la cultura cubana durante la primera mitad de esta centuria, nadie, creo yo, disputará a Carpentier un papel preeminente, casi solitario... Alejo no sólo nos mantuvo siempre en comunicación con medios culturales extranjeros al nuestro, sino que halló a toda hora el modo de divulgarlos, como un infatigable animador. Asi lo vemos reflejar durante los años 20 (a pesar de que los suyos eran cuatro menos que el siglo) los llamados entonces movimientos de vanguardia, sobre todo en música y literatura... La tribuna que Alejo Carpentier tuvo en casi todos los periódicos de La Habana, especialmente Carteles y Social, fue siempre un vínculo claro y esclarecedor de las novedades vigentes o iniciales en otros mundos bien alejados del nuestro. 
Son muchos los compartimentos y tonalidades en que ese gran retablo musical carpenteriano se parcela; son varios los cambios de orientación en que ciertas líneas estéticas fueron derivando según los tiempos que corrian y los derroteros estéticos; pero, del primero al último relato, hay constantes que nos atrevemos a atribuir a la recia personalidad del cubano.

En primer lugar, la orientación vanguardista del pensamiento artístico y musical, liberadora y por la que, haciendo paráfrasis revolucionaria, merece la pena matar o morir: "vanguardia o muerte"; nos lo ilustra en un raro ensayo, Tristán e Isolda en tierra firme, descatalogado por el propio autor:

[...] y fue en América Latina donde ciertos jóvenes se hicieron encarcelar, torturar y matar, por el Esprit Nouveau, ya que -el hecho es sobradamente conocido- hubo un momento, entre 1924 y 1930, en que todos los tiranos del Continente se dieron a desconfiar del cubismo y de las extrañas cosas que aparecian en las revistas llamadas entonces "de vanguardia", viendo en ellas las muestras de un espíritu subversivo" (Carpentier, 1949, 11).

Alejo retiró este ensayo de su catálogo de obras y tampoco lo incluyó en Tientos y diferencias, posiblemente por la referencia muy crítica a la "estética revolucionaria" y a la censura estalinista contra Dimitri Schostakovitch.

De todos modos, no olvidemos esa vertiente de la defensa de la vanguardia, tantas veces leída en clave marxista por el cubano, especialmente en sus apasionados discursos de radio o en alguno de sus prólogos; sirva como ejemplo este fragmento de una conferencia suya:

Creo [...] que un compositor que sea revolucionario, al expresarse libremente y si su calidad como creador es suficiente, dará precisamente la música que más convenga a la Revolución, aunque a los observadores superficiales pueda parecerles que no tiene ninguna relación con ella (Carpentier, 2003, 139).

En segundo lugar, el autor, con su impecable seguridad técnica al tratar el hecho musical, usará, en ocasiones con gran humor, las interioridades de la vanguardia para caracterizar, políticamente hablando, a sus personajes (conservadores vs progresistas); un recurso que aprende y perfecciona, sin duda, tras largas lecturas de Adolfo Salazar, como ya he observado anteriormente (Villanueva, 2009, 221). En este mismo sentido, he analizado en otro lugar (Villanueva, 2005b) esa técnica a partir de su novela El recurso del método (Carpentier, 2001), donde usa un mensaje marcadamente elitista, por el nivel que le exige al lector; y es que en lo musical Carpentier nunca hace concesiones, creando, sin proponérselo, una suerte de metalenguaje de profundo encanto, que también podemos disfrutar en Concierto Barroco (Carpentier, 1974), donde no sólo manipula y fuerza el verbo sino también el tiempo, haciendo coincidir en la gran "orgía veneciana" a autores barrocos con el tan admirado Igor Stravinsky.

Volviendo a El recurso del Método, el Primer Magistrado, ahora de paso por Nueva York "para apagar una de tantas asonadas", se convierte en el protagonista, portavoz y paradigma del aficionado burgués, incapaz de entender la vanguardia, atrofiado por el belcantismo y por el consumo de indigesto repertorio romántico, un prototipo tantas veces fotografiado en las crónicas carpenterianas:

Y como nada apremiante había de hacerse aquella noche, el Primer Magistrado, muy aficionado a la gran ópera, quiso escuchar un Peleas y Melisenda que se ofrecía en el Metropolitan Opera House, con la famosa Mary Garden en el papel principal. Mucho le había hablado el Académico, amigo de aquella partitura, que debía ser muy buena ya que, muy discutida al principio, tenía en París unos fanáticos admiradores a quienes al travieso maricón de Jean Lorrain había calificado de Peleastas... Se sentaron, pues, en primera fila, alzó su batuta el director, y una enorme orquesta que tenían ahi, a sus pies, empezó a no sonar. A no sonar, porque de ella se desprendía un murmullo, un estremecimiento, un cuchicheo de nota aquí, nota allá, que no llegaba a ser música. -" ¿Y no hay obertura?" -preguntaba el Primer Magistrado. -"Ya viene, ya viene" -decía Peralta, esperando que aquello empezara a crecer, a levantarse, a definirse, desembocando un fortísimo: "También Fausto y Aída comienzan así, como quien no dice nada; así (creo que a eso llaman sordina) para preparar mejor lo que viene después". Pero ya se alzaba el telón y se estaba en lo mismo. Esos músicos -estaban ahí, atentos, numerosos, puestos los ojos en las particellas- no acababan de hacer nada. Probaban sus lengüetas, sacaban la saliva de las trompas dando una media vuelta al instrumento, hacian vibrar una cuerda, barrían el arpa con la punta de los dedos, sin llegar a concretarse en una segura melodia. 
[...] Y cuando se llegó, por fin, al último intermedio, el Primer Magistrado estalló: "Aquí nadie acaba de cantar; nadie es baritono, tenor o bajo... No hay un aria... No hay un ballet... No hay una escena de conjunto.... Y el carajillo ese, americana nalgona vestida de niño, que mira por una ventana lo que pasa en el cuarto donde, no hay que decirlo, el jovencito buen mozo y la rubia de pelo largo están en lo suyo.... Y el cabrón de abajo que se desespera. Y el viejo ese, con cara de Carlos Darwin, que dice que si fuese Dios se apiadaría del corazón de los hombres (Carpentier 2001, 115-116).

Finalmente, como ampliaremos en la última parte del presente estudio, Carpentier desarrolla musicalmente el motivo de "las dos Españas" de diferentes maneras: tanto en el sentido "machadiano" como en el de la herencia de la "Madre Patria", tan presente en los relatos latinoamericanos que derivarán en el novelista cubano hacia diferentes subtemas extraordinariamente fecundos: entre otros, el afrocubanismo como salida histórica y estética. Véanse, como buen modelo, las diferentes aproximaciones al tema por parte de Victoria Eli $(1993,1087$, y 2009, 309), tanto desde el estudio de los tambores, como del sinfonismo de Amadeo Roldán y Alejandro García Caturla que Alejo orientó e historió. Y también, España como referente necesario y como "mala compañía"; los géneros teatrales (zarzuela y tonadilla enlazadas con la escena cubana); la España republicana que todos los latinoamericanos progresistas llevan en el corazón, etc. En todo caso, la formación carpenteriana, aunque francesa por parte de padre y cosmopolita por propia peripecia, es perfectamente española en los referentes literarios y musicales: géneros, danzas, autores, protagonistas, amigos y enemigos.

\section{La CONSAGRACIÓN DE LA PRIMAVERA}

Un rápido estado de la cuestión permitirá acercarnos más al detalle de la "banda sonora" de La consagración de la primavera; y digo esto porque Carpentier, metido profesionalmente desde 1929 en temas de sonorización de publicidad, radio, cine o teatro, tanto en París como en Caracas, considera el fondo musical de una narración como una suerte de soundtrack que debe encajar como un guante con el discurso narrativo, sin distorsionar ni distraer al lector. Además, le ayudará a contextualizar el relato, refrescando su memoria con canciones, melodias o referentes para ese lector, necesariamente muy informado, en el caso de El recurso del método, o no tanto cuando la historia nos habla didácticamente, como es el caso, de las grandes revoluciones del siglo XX y de canciones o de personajes que pertenecen ya a la memoria colectiva. De la conveniencia de que exista este maridaje texto-música/imagen-música, como en el caso de anuncios, películas o documentales, da buena cuenta esta carta dirigida por Carpentier al productor de la película El recurso del método, que rodaba el chileno Miguel Litín en 1978, y cuya música habían encargado al compositor cubano y reconocido guitarrista Leo Brower²:

Paris 12 de febrero de 1978/ Mi querido Alfredo,

a) tema de una conferencia

b) La música de la película.

(...) Michel Ray me dice que ya está sumamente adelantado el montaje, y que ahora va a proceder a la sincronización. Yo tengo confianza absoluta en el talento de Leo Brower. Pero me extraña que no me haya pedido algunos datos, porque la música desempeña un papel capital en mi novela, como elemento que precisa las fechas de la acción. Y no creo que Leo tenga ni conozca esas músicas. El puede acompañar las escenas como considere mejor. Pero hay un elemento música-calendario que no debe olvidarse. Las escenas de Paris, justo anteriores a la Primera Guerra Mundial, deben acompañarse en ciertos casos (en el burdel, sobre todo) de músicas inequívocas como el vals "Amoureuse", de Rodolphe Berger, que fue un éxito mundial de 1900 a 1914.

Cuando termina la guerra, "Yes, we have no bananas" y "Titina" (que fue una peste en La Habana).

Cuando haya alusiones a la guerra misma, no puede faltar el Over there del ejército americano, ni el Tipperary del ejército inglés, ni la Madelon de los franceses (los ingleses son de una inteligencia extraordinaria en el uso de tales músicas de época).

$Y$ durante la guerra que acontece en América Latina, deben oírse "La Adelita" mexicana: el "Adiós, adiós, lucero de mi vida", como aparece en el texto. Y la muerte del primer magistrado debe acompañarse de reminiscencia de canciones y música latinoamericanas anteriores a los años 30.

Ojo, las músicas europeas a las que me he referido, están todas disponibles en un fondo especial de la casa Francis Salabert.

Y ahora, por acabárseme el papel, un fuerte, fuerte, fuerte abrazo, de Lilia y mío. / Alejo. 
Cuando Carpentier decida narrar una gran crónica sobre la Revolución (a partir de otros relatos cortos que se fueron adjuntando al gran relato final), como estudian desde diversos ángulos Pablo Montoya (2001), Ambrosio Fornet (2008), o Rita de Maeseneer (1991), entre otros, va a tener muy presente el más mínimo detalle de las canciones que allí interpretan los brigadistas, tomadas del cancionero de Erns Bush (1978), o que escuchan o reproducen los que por alli transitan: testigos y notarios de las tres revoluciones. El tema de las fuentes usadas por Alejo ha sido tratado in extenso y con gran competencia por Carmen Vásquez (1981 y 2008), que era, por aquellos años de gestación de la obra, la principal documentalista de Carpentier.

Ese concepto de la música calendario, definido en la anterior carta, es vital para el cubano, como reitera en crónicas, entrevistas y conferencias. $Y$ es que, además de la importancia del "calendario de la memoria", hay en ello una manifestación expresa de homenaje universal a las tres revoluciones, que culminan con la última reafirmación en Playa Girón. Y sobresaliendo de entre todos los capítulos la admiración "sonora" a las brigadas internacionales, a la lucha contra el fascismo mediante la reivindicación de la música "negra" (música de jazz, antillana, afrocubana, etc.) y al supuesto mundo sonoro de la Segunda República.

Sin duda, la zarzuela será un buen pretexto en sus crónicas para retrotraernos a la vida teatral habanera de los "felices años 20": Ios entresijos de la escena, las distintas compañías, la valía de los cantantes o la presencia de grandes compositores españoles en la Isla (Carpentier, 1925). Una reflexión más profunda de la zarzuela y de la escena de tradición española en general (sainetes, tonadiIlas, cuplés, revista, etc.) procede de las vivencias del cubano durante sus diferentes visitas a España (Carpentier, $1934 ; 1937$ y 1939) y de la lectura directa de José Subirá, asuntos que yo he desarrollado en diferentes ocasiones (Villanueva, 2005 y 2009). Madrid viene a ser el centro de la nostalgia carpenteriana, con técnicas narrativas próximas a las del lenguaje cinematográfico, como indica Reix-Baxter (1982, 5):

In a sense, Carpentier's novels are films, already provided with setting, lighting and soundtrack as well as actors. All those elements are integral.
Este entusiasmo se refleja, de manera especial, como ya venía haciendo Adolfo Salazar, en la conexión de los géneros españoles más populares con la vanguardia más refinada de Manuel de Falla, como podemos comprobar en este fragmento:

Independientemente del valor de las partituras, es indudable que Blas de la Serna, Estévez, Misón, Manuel García, autores clásicos del Teatro de los Caños del Peral, de Madrid, escribieron pequeñas piezas líricas donde el idioma español aparece tratado de modo magnífico, dictando a menudo, con sus propias inflexiones, la materia melódica. $Y$, en el mismo terreno, debe reconocerse que "La verbena de la Paloma" o "La Revoltosa", por no citar sino dos casos significativos, se erigen en ejemplos perfectos en cuanto al tratamiento del castellano. Pero la zarzuela es la zarzuela y por lo mismo ese tipo de composición frívola -único que puede cultivarse con algún beneficio económico en la Península- ha menguado sus impulsos primeros de compositores tan estimables como Moreno Torroba, los músicos serios de nuestra América muestran una suerte de repugnancia en guiarse por normas de escritura nacidas de un género ligero y baladí. Lo cual no pasa, sin embargo, de ser un grave error. Manuel de Falla, que se mostró muy inteligente en su acuciosa indagación de lo hispánico, no tuvo reparo en estudiar los patrones vocales de la zarzuela. Quien conozca la "nana" que se inscribe en la partitura de "La verbena de la Paloma" sabrá de dónde derivan ciertas inflexiones, ciertos "modos de hacer", de las "Siete canciones" (Carpentier, 1958a).

0 este otro retazo de "Bajo el signo de la Cibeles", relato de pre-guerra trasladado casi literalmente a La consagración:

[...] Cada vez que me hallo en Madrid, me vuelvo espectador asiduo de los teatros de zarzuela y género chico. Después de asistir a cien representaciones de teatro avanzado, de óperas y de ballets nuevos por su estética, su técnica o su ideología, me veo siempre maravillado por el extraordinario primitivismo escénico del típico espectáculo español. Agua, azucarillos y aguardiente, El dúo de la Africana, El santo de la Isidra o La Revoltosa tienen para mí todo el encanto de una evocación de la "comedia del arte" italiana -origen de nuestro teatro- por el carácter improvisado de la interpretación, de la escenografía, por la ingenuidad de las intrigas, por la puerilidad de los chistes y situaciones cómicas. Tengo siempre la sensación de hallarme ante un enorme guiñol, 
animado por marionetas humanas... ique se tomen en serio! Hay un buen señor que aparece en escena dando gritos, porque unos ladrones lo han dejado en paños menores en el medio de la calle... (Carpentier, 1934).

De cualquier modo, y aunque no sea éste el espacio más adecuado para desarrollarlo, tampoco debemos olvidarnos de que Alejo participó como letrista en diferentes aventuras escénicas con su grupo El Tinglado, de 1927, con La hija del Ogro, con música de Amadeo Roldán, en donde seguía las directrices de La Barraca o del teatro de Rafael Alberti, autor muy admirado por el cubano, precisamente por la función social y política de su obra escénica. De hecho, El Milagro de Anaquillé, y otras obras "menores" de aquella época, todas del mismo corte, guardan estrecha relación, en espíritu, intenciones y estructura escénica, con las directrices del teatro político más esquemático y popular de Alberti, autor que aparece varias veces citado en La Consagración... Carpentier también nos indica que en Anaquillé o en la Rebambaramba no puede hablarse propiamente de obras escénicas: "Mis textos destinados al teatro -nos dice en una entrevista-, dos ballets y una ópera bufa, están concebidos para músicos y en función de la música. Sin la música que los acompaña, no tendrían vida autónoma" (Del Río, 1974, 321).

Resulta igualmente oportuno recordar su admiración extrema hacia el mundo de las marionetas como recurso ideal para conseguir materializar determinados mensajes sociales; Alejo estuvo siempre obsesionado con el resultado plástico de El Retablo, de Manuel de Falla; esto y su recuerdo juvenil de las marionetas de Vittorio Prodecca, en La Habana (en cuya pequeña orquesta tocaba el piano García Caturla), le Ilevan a reafirmarse en esta línea:

Confieso -nos dice- que los títeres me maravillan y conmueven... son sencillos, ingenuos, llenos de cualidades que hacian el encanto del teatro primitivo. $Y$ que los actores de hoy malograron con su perenne exaltación de un "yo" tan poco interesante como ficticio. Las marionettes tienen algo de esa poesía sutil que respiran los personajes cándidos de Giotto (...) con sus cuerpecitos de madera y cartón... me inspiran un santo respeto. No puedo olvidar que pertenecen a una raza augusta, tan gloriosa y vieja como los primeros tinglados de la primitiva farsa (Carpentier, 1980, t. I, 17).

\section{INTERTEXTUALIDAD}

Como ya indicaba Rodríguez Puértolas "La Consagración de la primavera ofrece, mucho más que otras novelas de Carpentier, una intertextualidad que bien puede clasificarse de continua, total, basada, sin duda, en conocimientos y lecturas en verdad enciclopédicos" $(1988,48)$. Ciertamente, en La Consagración, lo más destacable y brillante de entre esas polifonias intertextuales es, sin duda, todo lo que hace referencia a la música. Veamos algunos ejemplos.

En primer lugar, el tema introductorio de Stravinsky, que él recordará repetidas veces y al que acudirá como referente y metáfora durante toda su vida; motivo que llegó a ser, para muchos cubanos de su generación, "algo como un santo y seña que les hubiera abierto las puertas arcanas de un nuevo mundo sonoro" (Welter, 1984, 68). El propio Alejo nos lo apuntala:

Cuando viajé, hace muchos años ya, a las comarcas casi inexploradas del Alto Orinoco, no fui en busca de pintoresquismos ni de taparrabos: fui en busca de Le sacre $d u$ printemps. La flauta de un indio piaroa, casi desnudo, me hizo entender el tema inicial de la partitura de Stravinsky (Carpentier, 1994, 50).

También la idea del encuentro con lo primitivo, con la raíz de la vida, tiene un evidente paralelismo, aún siendo simbólico, con el colectivismo de la magia de la percusión, que para la africanía expusiera con minucioso y científico detalle Fernando Ortiz:

Este criterio animador [de los negros africanos] es más persistente con los objetos religiosos, los cuales suelen ser considerados como "personas" o habitáculos de "personas" sobrenaturales, aún cuando no sean ídolos o imágenes antropomorfas, sino, por ejemplo, simples piedras, caracoles, collares, tambores u otros objetos [...] Los tambores, sobre todo, son entes a los cuales hay que darles comida y trato "como gente" o como dioses... (Ortiz 1965, 126).

Aquella referencia a los tambores, en opinión de L. Ospovat (1986, 233-242), puede servir como punto de partida de la fascinación que sintió Carpentier por Igor Stravinsky y, más concretamente, por el ballet La Consagración de la Primavera, como base del sacrificio colectivo presente en las infinitas combinaciones ritmicas que se encuentran en 
la metáfora política que subyace, y que fundamentan sus primeras tesis africanistas sobre el nacionalismo cubano. ¿Se puede explicar mejor o de otro modo el título elegido por Carpentier para su novela?

Tanto el primitivismo como el colectivismo, con su homenaje a esa música de esclavos, los plasma Carpentier en brillantes referencias musicales:

Tras un bar oliente a ron del bueno, rodeados de gente que bailaría hasta después del amanecer, me esperaban los Ancestros todos de un mundo -mundo nacido del mestizaje de dos mundos- que, a falta de mejor definición, veía yo como un mundo tercero, o mejor: un Tercer Mundo, nacido de indios, negros y españoles. [...] Pero ahora resultaba que Osain-el-de-un-solo-pie [deidad cubana], señor de los ciclones, genio de la rotación, de la danza giratoria, en una órbita que iba de las bocas de Mississippi a las bocas del Orinoco, se habian echado a andar bailando, y bailando, bailando rumbas, congas, sones, calipsos, contradanzas criollas, arrastrando el blues en su comparsa endiablada, se habia instalado en París, en Londres, en Madrid, con el estimulante estruendo de su ctónica batería. Tras el drum de Nueva Orleáns, habian Ilegado en escuadrón cerrado, las claves y maracas, bongoes, timbales, güiros, cencerros, chachas, dientes de arado, econes, marímbulas, de Cuba... (Carpentier, 1998, 186).

0 esta otra sobre la "milagrosa" captación del ritmo sobre el papel:

Traté de ver lo que escribía [la nueva amiga alemana]: era música, evidentemente, puesto que había notas, con barritas de esas que llaman corcheas. Pero yo tenía entendido que la música se escribía sobre cinco líneas (¿pentagrama?) y la rara parroquiana esta lo apuntaba todo sobre una sola raya horizontal -a veces dos- sin que las notas parecieran subir o bajar. A veces se acercaba al estrado de la orquesta, observaba atentamente a Barreto, y regresaba a su cuaderno con el lápiz entre dientes. [...] Estuvo trazando signos indescifrables para mi con tintas roja y negras: "En negro las constantes" -decía-, "en rojo lo que se sale del encuadre" (Carpentier, 1998, 190-191).

Alejo Carpentier, además, preparará el gran clímax del canto de un espiritual negro y de La Internacional, con toda una serie de reflexiones, recuerdos, vivencias, de los Briga- distas incorporados desde Cuba y que servirán de puente entre las dos revoluciones; un crescendo que adelanta lo que será el gran tutti final:

En este minuto hago mía la consigna hasta ayer remota: "EL FRENTE POPULAR DE MADRID ES EL FRENTE POPULAR DEL MUNDO". Vivir en dimensión mayor -dias, semanas, meses, ¿quién sabe?- aunque fuera al precio de una existencia hasta ayer inútil. -"Ven acá, Gaspar... ¿qué debo hacer para irme contigo a las Brigadas?" -"Inscribirte. Mañana te llevo. Hay veinte cubanos más que acaban de llegar" (Carpentier, 1998, 221).

La entrada en escena de los espirituales negros constituye, junto con el canto de la Internacional en diversas lenguas, el momento culminante de la materialización/metáfora del colectivismo y de la fuerza de esos "parias de la tierra" ahora unidos contra el imperialismo. Al comentar la intervención de Paul Robeson el autor va "contrapunteando" el tema central del canto con reflexiones sobre la decadencia del imperialismo, o sobre la "nueva Babilonia" y su "becerro de oro", que serán destruidos por la Revolución Castrista:

Y fue la impresionante antífona llevada por el negro de New Jersey con responso de los muchos que aqui hablaban o entendian el inglés -y me explicaba Gaspar. Señalando hacia aquí o hacia allá, que con nosotros había gente de Jamaica, Australia, Canadá y Filipinas, y hasta surafricanos que, con su acción en las Brigadas, luchaban, en frente distante, contra algo que llamaban apartheid, palabra desprovista, para mí, de todo significado....Pero pronto, fuesen de donde fuesen todos los que me rodeaban, arrastrados por el ritmo, por la casi litúrgica recepción de una frase, se iban sumando al coro, por grupos, como un "amén" de oficio religioso: / Join in the fight, / 0 negro comrade./ Join in the fight.

[...] - ¡Carajo! ¡Cómo canta el negro este" -aulló Gaspar Blanco, cuando Robeson remató el "Spiritual" a la vez agresivo, unánime y fuera de fronteras, con el re bemol grave que sobre la palabra "mundo" daba a su voz una resonancia de tubo de órgano en vasta nave de catedral fraterna, de donde negros y blancos hubieran de surgir para echar abajo las perecederas torres de Babilonia (y ahora cantaba Robeson algo que trataba de Babilonia, precisamente), tantas veces comparadas, en la moderna literatura norteamericana, con los rascacielos de Manhattan. Y el nuevo blues se nos volvía increíblemente bíblico, en su rincón de costa española, evocando al David, vencedor de Goliat, que con su triunfan- 
te honda descornaría, de paso, al Becerro de Oro de Wall Street, acabando con todos los Leviatanes del universo. [...] La música me llegaba a las entrañas, sin quebrar la coraza que me defendía de las palabras. Me sabía más fuerte que las palabras y nunca se me había conquistado con palabras (Carpentier, 1998, 257-259).

Antes de entrar en batalla, se hace imprescindible, por otra parte, la aparición de La Internacional cantada en diferentes lenguas, precedida de otros cantos revolucionarios entonados por alemanes, franceses, italianos, catalanes 0 cubanos; no faltan referencias a los héroes españoles de las trincheras, a las canciones de García Lorca (tantas veces recordado por Carpentier como el mártir por excelencia del franquismo), o al cálido recuerdo de personajes imprescindibles en los encuentros de los intelectuales antifascistas de 1937: Manuel Altolaguirre, Rafael Alberti, Miguel Hernández, Luis Cernuda, Vicente Aleixandre, o León Felipe:

Se fueron los de la Carmagnole y el Ça ira, y un coro de Brigadistas, que mezclaba gente de los más diversos países (advertí la presencia, para mí inequívoca, de algunos rusos, acaso aviadores -"más bien técnicos", me dijo Jean-Claude), cantó la lenta, majestuosa, grave y muy eslava melodía de los Partisans, que con su tonalidad algo ensombrecida por la presencia de cuatro bemoles en la armadura, más parecía un nostálgico lamento que un himno enardecedor... Luego vinieron los italianos con La canción de los Garibaldianos y Bandiera rossa - pronto enlazada con Die Rote Fahne, entonada por los del batallón Edgar André [...] Con unos catalanes invitados tuvimos la solemne, amplia, casi arcaica melodía de Els Segadors -que, según me dijo Jean Claude, andaba desde el siglo XIV por tierras a dentro [...] Pero en eso, irrumpiendo de todas partes, trayendo panderos, zambombas, guitarras, instrumentos de romería y villancico, y hasta artefactos de hacer ruido de los que, sin duda, mencionaría alguna vez el arcipreste de Hita, llenaron el escenario los españoles... $Y$ en alegre ambiente, más regocijado que guerrero, sonó el vito del Quinto Regimiento... seguido de la tonada Los cuatro muleros que a estas horas ya habia dado la vuelta al mundo (hacía tiempo que se oía en París) con sus nuevas coplas, coreadas ahora por todos -desde los búlgaros del Dimitrov, a los yankis del Lincoln, a los polacos del Dombroswski, pasando por los alemanes del Thälmann y del Elgar André, y los brigadistas de La Marsellaise, cada cual con su acento propio, lo cual comunicaba a las palabras, por momentos, una rara sonoridad de esperanto:
Puente de los Franceses/ Puente de los Franceses/ Puente de los Franceses

Mamita mía/ nadie te pasa/ nadie te pasa.

Madrid qué bien resistes,/ Madrid qué bien resistes,/

Madrid qué bien resistes,

/Mamita mía/ los bombardeos/ los bombardeos (Carpentier, 1998, 263-264).

Tampoco falta un nostálgico recuerdo entre líneas para la gran Antonia Mercé "La Argentina", a la que había hecho "responsable" de tantos y tan grandes "momentos españoles" en los escenarios de París:

Y, para cerrar la función, el general alborozo de lo que Jean-Claude veía, por el corte y el estilo, como emparentado con el Trípili-trápala de la tonada dieciochesca llevada por Granados a la partitura de Goyescas (y la había visto bailar yo por Antonia Mercé "La Argentina") y hasta con las coplas de Marabú, recogidas por el Amadeo Vives de Doña Francisquita; el Anda, jaleo, jaleo, que fue uno de los más enérgicos cantos de aquella terrible guerra en cuya victoria republicana confiaban todos los aquí reunidos en esta noche sin más estrellas -porque estaba el cielo nublado- que las de ciertos uniformes, y la grande, roja, de tres puntas, que adornaba el fondo del escenario:

\author{
Yo me subi a un pino verde/ por ver si Franco llegaba, \\ por ver si Franco llegaba. \\ Y solo vi un tren blindado,/ lo bien que tiroteaba \\ lo bien que tiroteaba \\ -Anda jaleo, jaleo... (Carpentier, 1998, 265-266).
}

En la tercera de las entregas de "España bajo las bombas", Carpentier se había referido ya a Antonia Mercé, promotora con sus ballets de autores tan significativos para él como Ernesto Halffter, Oscar Esplá o el propio Manuel de Falla. Siguiendo la estela de Salazar, Carpentier tenía las esperanzas puestas en E. Halffter como legítimo sucesor de Falla; de hecho lo incorpora a sus relatos míticos del Madrid del 36:

En las paredes, los carteles que ostentan el ya clásico "Defended Madrid" avecindan con otros que anuncian representaciones de Mariana Pineda de García Lorca, así como un concierto sinfónico dirigido por Bacarise, Halffter y el Maestro Sanjuán. Después de la tormenta todo respira alegria y voluntad de vivir (Carpentier, 1939). 
Ineludible asimismo le resulta el recuerdo de Pablo Casals, también presente en las crónicas desde Caracas; Alejo reincorpora al cellista catalán al relato de La Consagración por su valía como intérprete $y$, de modo especial, como símbolo universal del republicanismo en el exilio. No es casual que abra el párrafo dedicado a Casals comentando himnos fascistas, teniendo en cuenta la permanente lucha por la paz y contra el fascismo que abanderaba el cellista de El Vendrell:

\begin{abstract}
Nosotros estamos preparando la Obertura 1938: Victoria de La Internacional sobre Giovinezza y el Horst Wessel Lied. A lo mejor la oyes el año próximo, escrita por algún compositor español, y dirigida por Pablo Casals, que está con nosotros. Sí. Pablo Casals estaba dirigiendo conciertos en Barcelona. Había visto su nombre, tres dias antes, en un cartel. Pero no me imaginaba a Casals accionando una batuta. El arco era una prolongación natural de su mano. Hombre-violoncello, puesto que, cuando se instalaba tras de su instrumento, medio oculto por él, abrazado a él, reluciente la calva como barniz cremonense, el hombre se consustanciaba con el violoncello (Carpentier, 1998, 269-270).
\end{abstract}

Entre las tiras de su columna "Letra y solfa", ya había traido con pretextos varios al instrumentista catalán (Carpentier, 1955a, 1955b y 1958b), pregonero insigne de la República en los escenarios y ahora director del gran proyecto panamericano de la Sinfónica de Puerto Rico.

El tema de la relación de la música española, del romance a la décima, es otra de las grandes intuiciones carpenterianas, consistente en mezclar la materia prima española (décimas, romances y danzas) con la vitalidad rítmica aportada por los esclavos africanos que acudian desde Sevilla en los mismos barcos transculturales. Este recurso también está presente en La consagración:

\footnotetext{
Gaspar cantó una [canción], escuchada por él en una ciudad llamada Trinidad, que, según mi amante, vendría a ser una variante del romance de la Delgadina, tan difundida en el mundo que, según Menéndez Pidal, había Ilegado hasta Islandia. Y fueron reminiscencias de coplas de América, cantares del medioevo, presencia de Gerineldo, las tres moricas de Jaén, el Conde Alarcos, el Señor Don Gato, Bernardo del Carpio, La cautiva de Antequera, Melisenda, Don Gayferos, revueltos con tonadas de payadores, troveros, letras de corridos y fulias, refalosas y guarachas, hasta el crepúsculo... (Carpentier, 1998, 287).
}

Como ya dije en otro lugar, "las incursiones musicales en el siglo XVI y XVII [son] de una gran ocurrencia, riqueza de imágenes e ingenio narrativo al tratar tanto el tema de la transculturación de las danzas, presente en los testimonios de los escritores españoles del Siglo de Oro, como en la relación de las "décimas" y el romancero español, temas ambos de extraordinario interés en su planteamiento" (Villanueva, 2005a, 331).

\section{Coda}

Es muy posible, como ya vimos, que La consagración de la primavera, la última novela grande de Alejo Carpentier, se hubiese quedado en pequeños relatos y crónicas de no haber mediado una polémica con Neruda y con otros escritores latinoamericanos del círculo de París de los 70 . El crecimiento de su impacto como narrador, el gran desarrollo de sus tesis sobre "lo real maravilloso" y el reconocimiento internacional de su singularidad como guía intelectual de una importante corriente de la narrativa iberoamericana, no apagaron las líneas maestras de un pensamiento político firme y persistente. La música, su primera dedicación como periodista, ensayista o historiador, se integra en esa recia estructura literaria con la idea básica y la función de lo que definió como "música calendario", que debe contextualizar con rigor cualquier relato; una propuesta, quizá, no totalmente original pero que nadie como él supo materializar en palabras, dada la precisión técnica y la belleza formal alcanzada por su prosa.

El relato musical que se integra en novelas, crónicas o ensayos contiene los elementos "políticos" básicos que hemos ido desarrollando: búsqueda incondicional de la vanguardia, lucha por un público abierto a la modernidad, y búsqueda de la libertad mirando a lo propio, fuera de dependencias no deseadas. La consagración de la Primavera, además del componente épico que atesora, supone el cuadro musical más variado, enriquecedor y comprometido de cuantos escribió el narrador cubano: una enciclopedia en la que se encuentran el erudito mundo carpenteriano y toda la belleza de la música hecha palabra; pero palabra sincronizada, densamente politizada y profundamente atractiva: la mejor banda sonora posible para "lo real maravilloso".

Santiago de Compostela, 4 de noviembre de 2010 
1 Fondo Alejo Carpentier; Biblioteca Nacional José Martí de La Habana (BNJM), CM 258.

2 BNJM, CM258. Tema: Sonorización de El recurso del método. Sobre la película, vid. http://www.imdb.es/title/ tt0078146/ consulta del 4/10/2010.

\section{BIBLIOGRAFÍA}

Baujín, José Antonio (2003): Rutas carpenterianas para un diálogo con la obra de Valle-Inclán, Tesis doctoral, Facultad de Artes y Letras, Universidad de La Habana (consultada por gentileza del autor).

Brennan, Timothy (1977): At home in the world, London, Harvard University Press.

Bush, Erns (ed.) (1978): Cancionero de las Brigadas Internacionales, Barcelona, junio de 1938, ed. facsímil, Madrid, Nuestra Cultura, 1978.

Cairo, Ana (1978): El grupo Minorista y su tiempo, La Habana, Ciencias Sociales.

- (1988): "La década genésica del intelectual Carpentier (1923-1933)", Letras. Cultura en Cuba, n. 5 (Ana Cairo, ed.), Editorial Pueblo y Educación, La Habana.

- (2005): "Martín, Carpentier y España", Actas del Coloquio del Centenario Alejo Carpentier, Santiago de Compostela, marzo de 2004, Servicio de Publicaciones Universidad de Santiago.

Carpentier, Alejo (1925): "Nuestro entrevistado: hablando con el Maestro Vives", Carteles, 22/2/1925.

- (1934): "Bajo el signo de la Cibeles", Carteles, 30/9/1934.

- (1937): "España bajo las bombas" Carteles, 12 sept. y 26 de sept.

Recibido: 25 de octubre de 2010 Aceptado: 15 de enero de 2011

- (1939): "España bajo las bombas" Carteles, 20 oct. y 31 de oct.
- (1946): La Música en Cuba, México DF, Fondo de Cultura Económica.

- (1949): Tristán e Isolda en tierra firme, Ensayos americanos, Caracas, Imprenta Nacional, 1949.

- (1955a): A. Carpentier, "Casals habla de Bach", El Nacional, 3/3/1955.

- (1955b): "Una inesperada revelación", El Nacional, 9/3/1955.

- (1958a): "Los compositores y el idioma", El Nacional, 8/10/1958.

- (1958b): "Casals funda una orquesta", El Nacional, 6/8/1958.

- (1964): Tientos y diferencias. Ensayos, México, UNAM.

- (1979): Bajo el signo de la Cibeles, Crónicas sobre España y los españoles. 1925-1937, J. Rodríguez Puértolas (comp.), Madrid, Nuestra Cultura.

- (1980): Ese músico que llevo dentro, (selección de Zoila Gómez), La Habana, Letras Cubanas.

- (1994): Temas de la lira y del bongó, (selección de Radamés Giro), La Habana, Letras Cubanas.

- (1998): La consagración de la Primavera, Julio Rodríguez Puértolas (editor), Madrid, Clásicos Castalia.

- (2001): El recurso del Método, José A Baujín (ed.), Santiago de Compostela Servicio de Publicaciones de la USC.

- (2003): "Roberto Fernández Retamar y José Ardévol", La cultura en Cuba y en el mundo. Conferencias en Radio Habana (1964-1966) (José Antonio Baujín, Ed.), Letras Cubanas, La Habana; conferencia n. ${ }^{0} 20$, p. 139.

Eli, Victoria (1993): "El Caribe: unidad y diversidad de su cultura musical", Revista de Musicología, vol. 16, n. 2 (1993) 1087.

- (2009): "El afrocubanismo, un cambio de estética en la creación musical académica de Hispanoamérica", Revista de Musicología, vol. 32, n. ${ }^{2}$ 2, 309.

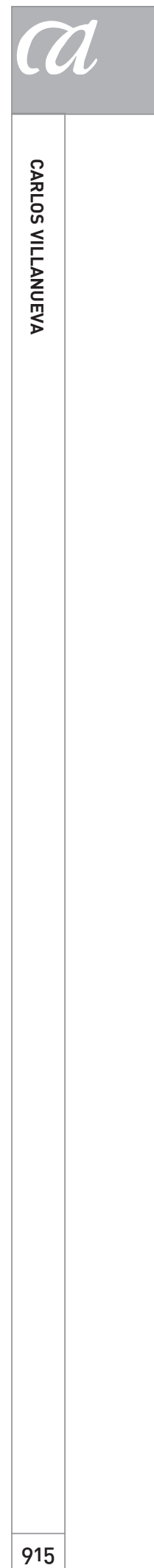


Espaces d'Alejo Carpentier (Jean Lamore, ed.), Presses Universitaires de Bourdeaux.

Garcia-Carranza, Araceli (1984): Biobibliografía de Alejo Carpentier, La Habana, Letras Cubanas, 1984; y

- (1989): Biobibliografía de Alejo Carpentier (suplemento I), La Habana, Biblioteca Nacional José Martí.

- (2005): "Presencia de España en la obra de Alejo Carpentier: una aproximación bibliográfica complementaria y crítica", Actas del Coloquio del Centenario Alejo Carpentier, Santiago de Compostela, marzo de 2004. Servicio de Publicaciones Universidad de Santiago.

Giro, Radamés, compilador (1994): Alejo Carpentier. Temas de la lira y del bongó, La Habana, Letras Cubanas.

Gómez, Zoila, compiladora (1980): Alejo Carpentier, Ese músico que llevo dentro, La Habana, Letras Cubanas.

González Echevarría, Roberto (1998): Mito y archivo. Una teoría de la narrativa latinoamericana, México D.F., Fondo de Cultura Económica.

- (2004): "Carpentier, el extranjero", Artes y Letras de El Mercurio (Santiago de Chile), 12 de diciembre. http:// www.letras.s5.com/ac021104.htm, consulta 5/10/2010.

Guillén, Nicolás (1974): Discurso en la Unión Nacional de Escritores y Artistas de Cuba, 28 dic. 1974, en Un Camino de medio siglo: setenta aniversario de Alejo Carpentier, La Habana, 1976, pp. 53-57.

Janney, Franck (1981): Alejo Carpentier and his Early Works, London, Tamesis Books Limited.
Maeseneer, Rita de (1991): Alejo Carpentier, La consagración de la Primavera. Una in-cita-ción, Universidad de Gante. Tesis doctoral (consultada por gentileza de la Fundación Carpentier).

Marinello, Juan (1937): Literatura hispanoamericana, Universidad Nacional de México.

Montoya Campuzano, Pablo (2001): La musique dans l'ouvre d'Alejo Carpentier Tesis doctoral de la Université Paris III-Sorbone Nouvelle. Defendida el 13 de oct. de 2001 (consultada por gentileza de la Fundación Carpentier).

Neruda, Pablo (1974): Confieso que he vivido, Buenos Aires, Losada.

Ortiz, Fernando (1965): Africanía de la música folklórica de Cuba, Universidad Central de las Villas, La Habana.

Ospovat, Lev (1986): "Música de la Revolución", Imán, Año III, 233.

Portuondo, Juan Antonio (1976): "Prólogo". A. Carpentier. Crónicas, tomo I, La Habana.

Reid-Baxter, James (1982): A certain Unity of Purpose: Alejo Carpentier and his novel "La Consagración de la Primavera", Tesis para el grado de Ph.D. Universidad de Aberdeen.

Río, Salvador del (1974): "Conversación con Alejo Carpentier", Revista Mexicana de Cultura, n. ${ }^{\circ}$ 305, México DF, 8 de diciembre de 1974.

Rodríguez Puertotas, Julio (1998): Prólogo y estudio de Alejo Carpentier, La consagración de la Primavera, Madrid, Clásicos Castalia.

Vargas Llosa, Mario (2010): "Catorce minutos de reflexión", El País (Madrid) 10/10/2010.
Vásquez, Carmen (1978): Robert Desnos et le monde hispanique. Université de Paris III (mecanografiada, por gentileza de la autora).

- (1981): "Mis años de trabajo con Alejo Carpentier", Sin nombre, San Juan de Puerto Rico, vol XII, n.o 2 (1981) 107.

- (2008): "Alejo Carpentier, el comienzo", Espaces d'Alejo Carpentier (Jean Lamore, ed.), Presses Universitaires de Bourdeaux, p. 13

Villanueva, Carlos (2005a): "La Música española en Alejo Carpentier", Actas del Coloquio del Centenario Alejo Carpentier, Santiago de Compostela, marzo 2004. Servicio de Publicaciones Universidad de Santiago, p. 323.

- (2005b): "Y el Sonido se hizo Palabra: escuchando fragmentos de Alejo Carpentier", Quintana. Revista del Departamento de Arte de la USC, n. ${ }^{\circ} 4$, p. 117.

- (2008): "Alcance del concepto Nacionalismo musical en la obra de Alejo Carpentier", Espaces d'Alejo Carpentier (Jean Lamore, ed.), Presses Universitaires de Bourdeaux, p. 45.

- (2009): "Adolfo Salazar y la crítica musical. Las otras orillas", Música y Cultura en la Edad de Plata 19151939, María Nagore et al. (eds.), Madrid, ICCMU, 2009, p. 221.

Welter, Ingela (1984): Presencia y función de La consagración de la primavera en la novela "La consagración de la primavera" de Alejo Carpentier. Disertación de Licenciatura, Universidad de Goteborg (consultado por gentileza de la Fundación Carpentier). 